\title{
Synthesis, crystal structure and antifungal activity of dihydroisoquinoline Oxaziridines Substitued in Position 1
}

Mouna BOUZID ${ }^{(\mathrm{a})}$, Raed ABDENNABI ${ }^{(\mathrm{b})}$,Chakib HRIZI $^{(\mathrm{c})}$, Neji GHARSALLAH ${ }^{(\mathrm{b})}$ and Majed KAMMOUN $^{(a) *}$

(a) Laboratory of Chemistry of Natural Products, Sfax University, Faculty of Science BP 1171, 3000 Sfax,

Tunisia. ${ }^{(b)}$ Laboratory of Plant Biotechnology Applied to Crop Improvement, Sfax University, Faculty of Science BP 1171, 3000 Sfax, Tunisia.

(c) Laboratory of Materials Science and Environment, Sfax University, Faculty of Science BP 1171, 3000 Sfax, Tunisia

*Corresponding authors: majed_kammoun@yahoo.fr.

\section{ABSTRACT}

We report here the synthesis and the X-ray crystallography of dihydroisoquinoline oxaziridines with methyl substitute in position 1 and with nitro group in position 7 (compound 3b). We also synthesized the compound 3a without nitro. These compounds have been prepared by the peracidic oxidation of imines with m-chloroperbenzoic (m-CPBA) like oxidizing agent. This two compounds exhibit higher antifungal activity.

\section{Keywords}

Oxaziridine; m-CPBA; X-ray diffraction; Antifungal activity.

\section{Council for Innovative Research}

Peer Review Research Publishing System

Journal: Journal of Advances in Chemistry

Vol. 10, No. 4

editorjaconline@gmail.com 


\section{INTRODUCTION}

Oxaziridines, heterocyclic compounds containing oxygen, nitrogen and carbon atoms in a three member ring, were first reported in the mid-fifties by Emmons ${ }^{[1]}$. Extensive investigation of these compounds have revealed their unusual reactivity, undoubted related to the presence of the strained three-member ring and a relatively weak N-O bond.

These heterocyclic have been shown to be promising reagents with potential antitumor ${ }^{[2,3]}$, anti-malarial ${ }^{[4]}$, and antifungal activities ${ }^{[5]}$, and penicillin analogs ${ }^{[6]}$. They are also widely used as reagents and intermediates in the preparation of biologically active molecules ${ }^{[7,8]}$.

The currently available methodologies for the synthesis of these valuable compounds are, however, very limited. The major routes to the synthesis of oxaziridines involve the photoisomerization of nitrones ${ }^{[9]}$, the electrophilic amination of carbonyl compounds ${ }^{[10]}$, the double 1,4-conjugate addition of hydroxamic acids to propiolates, and the oxidation of imines with several oxidizing agents, such as peracid ${ }^{[11]}$, oxone ${ }^{[12]}$, hydrogen peroxide ${ }^{[13]}$, or a nitrilehydrogen peroxide system ${ }^{[14]}$.

Oxaziridines are usually known for their ability to react as aminating agents in their reactions with nucleophiles. In fact, $\mathrm{N}-\mathrm{H}^{[10]}, \mathrm{N}$-alkyl ${ }^{[15]}$, and $\mathrm{N}$-alkoxycarbonyl oxaziridines ${ }^{[16]}$ are used as electrophilic aminating agents ${ }^{[17]}$ Nevertheless, oxygen transfer may occasionally result only in exceptional cases.

The oxidation of sulfides to sulfoxides is a highly important synthetic transformation that has received much attention in recent years ${ }^{[18]}$. Asymmetric sulfoxides are very useful as synthons and chiral auxiliaries in asymmetric synthesis ${ }^{[19]}$.

In this paper, we reports the synthesis and the antifungal activities of two oxaziridines, namely $\mathbf{3 a}$ and $\mathbf{3 b}$ with methyl substitute in position 1.

\section{RESULTS AND DISCUSSION}

These two oxaziridines (3a and $\mathbf{3 b}$ ) were previously reported in our earlier work ${ }^{[20]}$ to be an agent for the transfer of oxygen on organosulfides, if the oxygen transfer is promoted by an acid.

The two oxaziridines presented in the current study were synthesized starting from the commercial tertiary alcohol 1 (Scheme 1). The imine $\mathbf{2}^{[21]}$ from step (a) was obtained by cyclization of the tertiary alcohol $\mathbf{1}$. The nitration of imine $\mathbf{2 a}$ under the soft conditions ${ }^{[22,23]}$ selectively led to the derived $\mathbf{2 b}$. The peracidic oxidation of imines $\mathbf{2 a}$ and $\mathbf{2 b}$ lead quickly to oxaziridines $\mathbf{3 a}$ and $\mathbf{3} \mathbf{b}$ with good yields, respectively (Scheme 1 ).

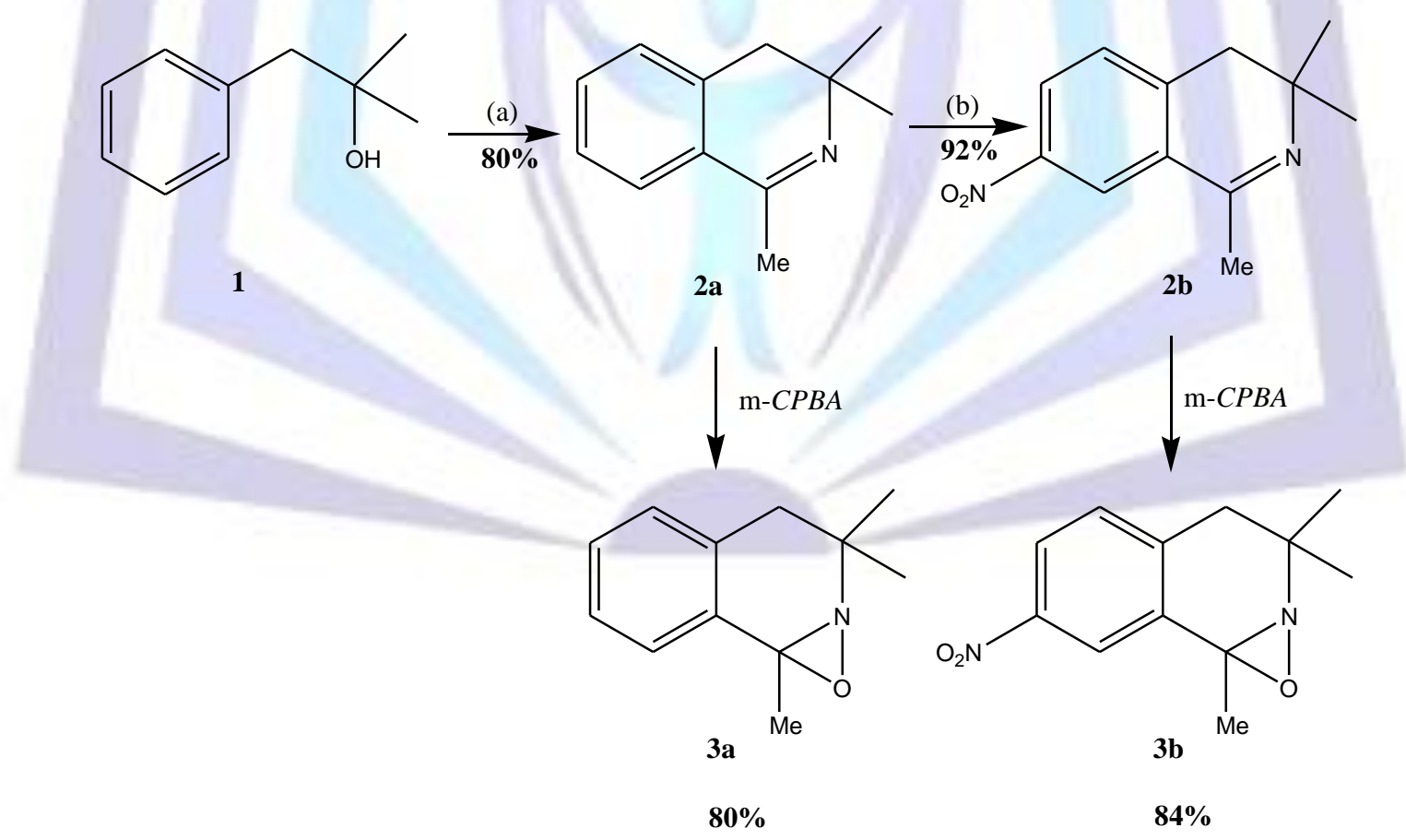

(a) : $\mathrm{H}_{2} \mathrm{SO}_{4}, \mathrm{CH}_{3}-\mathrm{CN}$, hexane $/ 3 \mathrm{~h}$ at $68^{\circ} \mathrm{C}$

(b): $\mathrm{KNO}_{3}, \mathrm{H}_{2} \mathrm{SO}_{4} / 2 \mathrm{~h}$ at $20^{\circ} \mathrm{C}$ than $4 \mathrm{~h}$ at $60^{\circ} \mathrm{C}$

Scheme 1: Synthesis of Oxaziridines 
The formation of oxaziridine $\mathbf{3 b}$ was further confirmed by the single-crystal $\mathrm{x}$-ray crystallographic analysis (Fig.1). The crystal data and parameters relevant to the structure determination and refinement for this compound are listed in table 1.

The molecular structure of the crystal with atom labeling and a view of the packing diagram along the axis are shown in Figures 1 and 2, respectively.

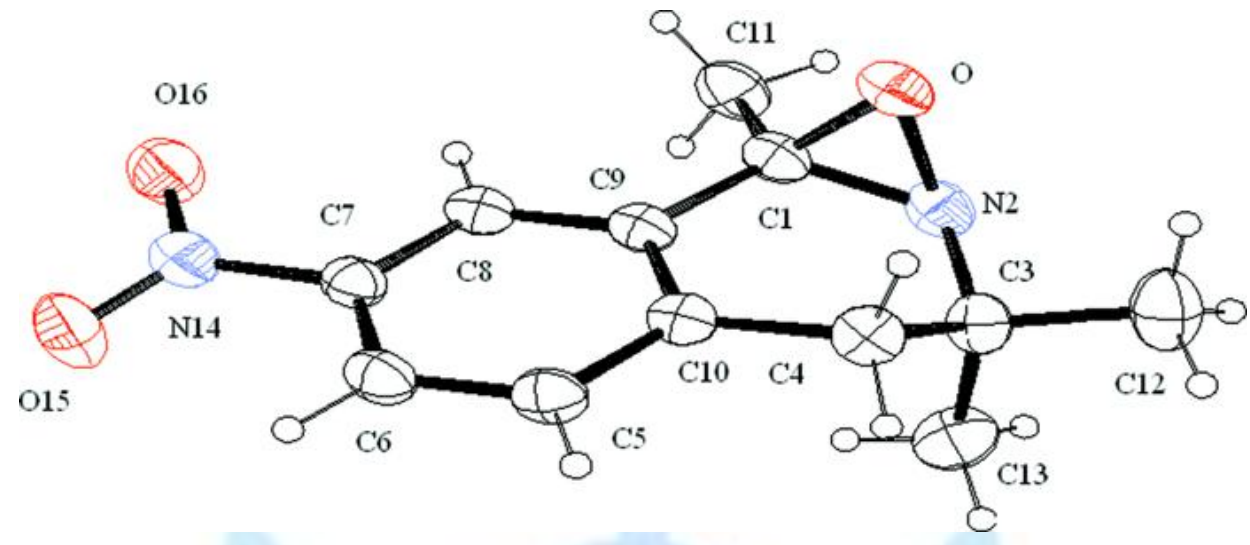

Figure 1: Molecular structure of the compound $\mathbf{3 b}$ with atom numbering

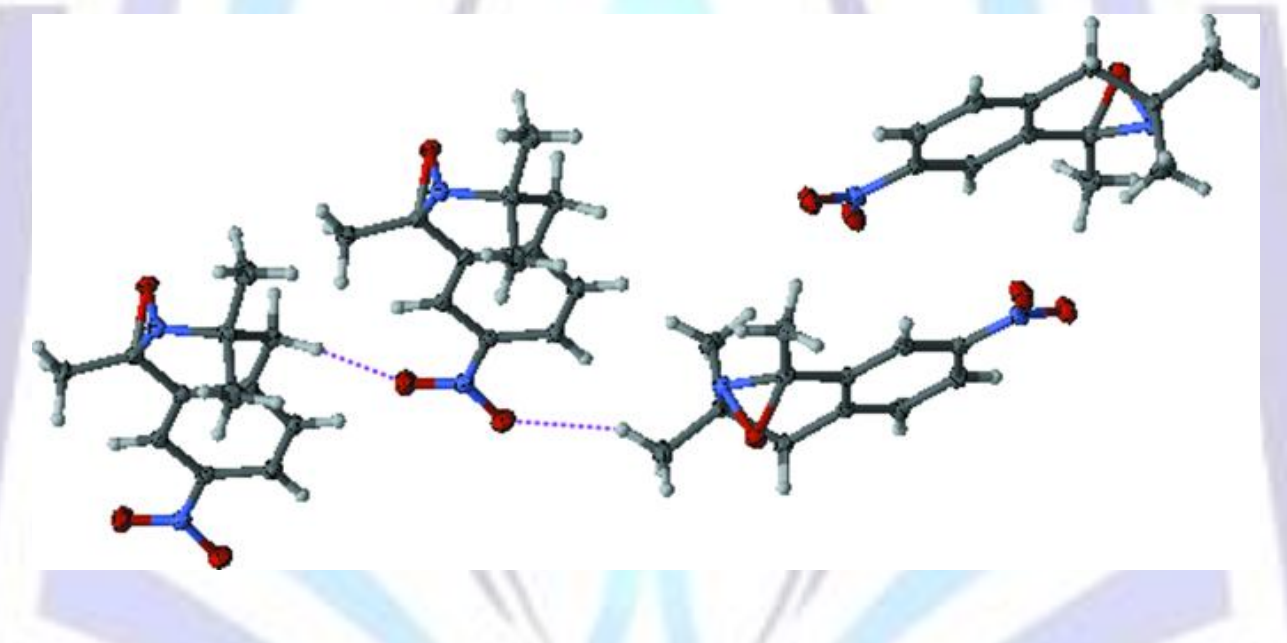

Figure 2: Projection along the axis of the atomic arrangements of compound $\mathbf{3 b}$

X-ray crystal structure of $\mathbf{3 b}$ discussion. The crystals $\mathbf{3 b}$ were obtained by recrystallization from pentane. For this compound (oxaziridine $\mathbf{3 b}$ ), systematic absences in the intensity data confirmed the space group $P 2_{1} / n$. Direct methods (SHELXS 79) [24] structure solution, difference Fourier syntheses, and full matrix least-squares refinement against $F^{2}$ were performed with SHELXTL ${ }^{[25]}$. In order to predict and/or interpret the reactivity of the oxaziridine, it is important to determine the orientation of the cycle of oxaziridine and the nitro functional groups. The X-ray crystallographic analysis of the 7-Nitro-1,2-oxydo-1,3,3-trimethyl-3,4-dihydroisoquinoline $\mathbf{3 b}$ revealed that the oxaziridine ring adopts a pseudoaxial conformation. The dihedral angle between the best planes through the phenyl ring built up by the atoms (C5 C6 C7 C8 C9 $\mathrm{C} 10)$ and the cyclic system built up by (C1 N2 C3 C4 C10 C9) is $14.6(1)^{\circ}$, and the dihedral angle between the ring (C1 N2 C3 C4 C10 C9) and the group built up by the atoms (C1 N2 O) is $97.16^{\circ}$.

This compound $\mathbf{3 b}$ (Fig.2) was stabilized by two inter-molecular hydrogen bonds (C4-H4A …016, $2.57(1) \AA$, $155(1)^{\circ}$

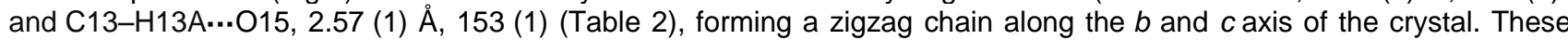
layers were parallel to the $b c$ plane and built up a three-dimensional framework by inter-molecular $\pi \cdots \pi$-stacking interactions. There are connected by Van Der Waals forces. The stacking is observed along the a axis with distance 3.4630 (16) Å between the layers of oxaziridine and phenyl rings [centroid-centroid distance 3.7761(18) $\AA$ ] . 
Table1. Selected geometric parameters $\left(\AA{ }^{\circ}{ }^{\circ}\right)$.

\begin{tabular}{|c|c|c|c|}
\hline $\mathrm{C} 11-\mathrm{C} 1$ & $1.499(3)$ & $\mathrm{N} 2-\mathrm{C} 3$ & $1.486(2)$ \\
\hline $\mathrm{C} 9-\mathrm{C} 10$ & $1.398(2)$ & $\mathrm{N} 2-\mathrm{O}$ & 1.5099 (19) \\
\hline $\mathrm{C} 9-\mathrm{C} 1$ & $1.497(2)$ & $\mathrm{C} 10-\mathrm{C} 4$ & $1.490(2)$ \\
\hline $\mathrm{C} 9-\mathrm{C} 8$ & $1.384(2)$ & $\mathrm{C} 1-\mathrm{O}$ & $1.426(2)$ \\
\hline $\mathrm{C} 7-\mathrm{C} 6$ & $1.376(2)$ & $\mathrm{C} 4-\mathrm{C} 3$ & $1.528(2)$ \\
\hline $\mathrm{C} 7-\mathrm{N} 14$ & $1.465(2)$ & $\mathrm{N} 14-\mathrm{O} 15$ & $1.212(2)$ \\
\hline $\mathrm{C} 7-\mathrm{C} 8$ & $1.380(2)$ & $\mathrm{N} 14-\mathrm{O} 16$ & $1.215(2)$ \\
\hline C6-C5 & $1.370(3)$ & $\mathrm{C} 13-\mathrm{C} 3$ & $1.518(3)$ \\
\hline $\mathrm{C} 5-\mathrm{C} 10$ & $1.389(2)$ & $\mathrm{C} 12-\mathrm{C} 3$ & $1.515(3)$ \\
\hline $\mathrm{N} 2-\mathrm{C} 1$ & $1.446(2)$ & & \\
\hline $\mathrm{C} 10-\mathrm{C} 9-\mathrm{C} 1$ & $119.06(15)$ & $\mathrm{C} 9-\mathrm{C} 1-\mathrm{N} 2$ & $119.51(14)$ \\
\hline $\mathrm{C} 10-\mathrm{C} 9-\mathrm{C} 8$ & $119.50(14)$ & $\mathrm{C} 11-\mathrm{C} 1-\mathrm{O}$ & $114.59(14)$ \\
\hline $\mathrm{C} 1-\mathrm{C} 9-\mathrm{C} 8$ & $121.43(15)$ & $\mathrm{C} 9-\mathrm{C} 1-\mathrm{O}$ & $115.39(13)$ \\
\hline $\mathrm{C} 6-\mathrm{C} 7-\mathrm{N} 14$ & $119.13(15)$ & $\mathrm{N} 2-\mathrm{C} 1-\mathrm{O}$ & $63.42(11)$ \\
\hline $\mathrm{C} 6-\mathrm{C} 7-\mathrm{C} 8$ & $122.41(16)$ & $\mathrm{C} 10-\mathrm{C} 4-\mathrm{C} 3$ & $112.80(13)$ \\
\hline $\mathrm{N} 14-\mathrm{C} 7-\mathrm{C} 8$ & $118.45(15)$ & $\mathrm{C} 7-\mathrm{N} 14-\mathrm{O} 15$ & $118.79(16)$ \\
\hline $\mathrm{C} 7-\mathrm{C} 6-\mathrm{C} 5$ & $118.02(15)$ & $\mathrm{C} 7-\mathrm{N} 14-\mathrm{O} 16$ & $118.50(15)$ \\
\hline $\mathrm{C} 6-\mathrm{C} 5-\mathrm{C} 10$ & $121.58(15)$ & $\mathrm{O} 15-\mathrm{N} 14-\mathrm{O} 16$ & $122.71(17)$ \\
\hline $\mathrm{C} 1-\mathrm{N} 2-\mathrm{C} 3$ & $117.64(13)$ & $\mathrm{C} 9-\mathrm{C} 8-\mathrm{C} 7$ & $119.14(15)$ \\
\hline $\mathrm{C} 1-\mathrm{N} 2-\mathrm{O}$ & $57.63(10)$ & $\mathrm{C} 4-\mathrm{C} 3-\mathrm{C} 13$ & $108.73(15)$ \\
\hline $\mathrm{C} 3-\mathrm{N} 2-\mathrm{O}$ & $109.99(12)$ & $\mathrm{C} 4-\mathrm{C} 3-\mathrm{C} 12$ & $111.81(15)$ \\
\hline $\mathrm{C} 9-\mathrm{C} 10-\mathrm{C} 5$ & $119.32(16)$ & $\mathrm{C} 13-\mathrm{C} 3-\mathrm{C} 12$ & $111.15(18)$ \\
\hline $\mathrm{C} 9-\mathrm{C} 10-\mathrm{C} 4$ & $118.56(14)$ & $\mathrm{C} 4-\mathrm{C} 3-\mathrm{N} 2$ & $113.58(15)$ \\
\hline $\mathrm{C} 5-\mathrm{C} 10-\mathrm{C} 4$ & $122.12(15)$ & $\mathrm{C} 13-\mathrm{C} 3-\mathrm{N} 2$ & $106.82(16)$ \\
\hline $\mathrm{C} 11-\mathrm{C} 1-\mathrm{C} 9$ & $117.79(15)$ & $\mathrm{C} 12-\mathrm{C} 3-\mathrm{N} 2$ & $104.62(14)$ \\
\hline $\mathrm{C} 11-\mathrm{C} 1-\mathrm{N} 2$ & $114.61(15)$ & $\mathrm{N} 2-\mathrm{O}-\mathrm{C} 1$ & $58.95(10)$ \\
\hline
\end{tabular}

Table2. Hydrogen-bond geometry $(\AA \stackrel{\circ}{\circ})$.

\begin{tabular}{llllc}
\hline$D-\mathrm{H} \cdots A$ & $D-\mathrm{H}$ & $\mathrm{H} \cdots A$ & $D \cdots A$ & $D-\mathrm{H} \cdots A$ \\
$\mathrm{C} 4-\mathrm{H} 4 A \cdots \mathrm{O} 16^{\prime}$ & 0.9700 & 2.5700 & $3.4788(19)$ & 155.00 \\
$\mathrm{C} 13-\mathrm{H} 13 A \cdots \mathrm{O} 15^{\prime \prime}$ & 0.9600 & 2.5700 & $3.459(2)$ & 153.00 \\
\hline
\end{tabular}

Symmetry codes: (i) $x, y, z+1$; (ii) $-x+3 / 2, y+1 / 2,-z+1 / 2$. 
Antifungal activity These two compounds were evaluated for their antifungal activities against Verticillium dahliae and fusarium solani inoculated into a PDA. In the present study, antifungal activity of the compounds was performed using the method of diffusion.

The results obtained from the evaluation study are provided in Table 3 and it explains that these two compounds (3a and $\mathbf{3 b}$ ) have significant antifungal activity at $5 \mathrm{mg} / \mathrm{ml}$ against Verticillium dahliae and fusarium solani.

From our observations, we thought that the compounds $\mathbf{3 a}$ and $\mathbf{3 b}$ provide interesting biological properties, like those whom have a potential activity against the verticillose and the fusariose. Verticillose is caused by Verticillium dahliae, a soil borne pathogen, belongs to the fungal class Deuteromycetes (Fungi Imperfecti), a group of fungi, which do not have a known sexual stage. Symptoms vary among hosts, and none is absolutely diagnostic. Premature foliar chlorosis and necrosis and a tan to brown colored discoloration or streaking of the vascular system, however, are characteristic of all hosts. Symptoms of wilting are most evident on warm, sunny days. Microsclerotia formed in the dying tissue are frequently visible with a hand lens. The fusariose is caused by Fusarium virguliforme sp. nov., formally known as F. solani causes sudden death syndrome (SDS) in soybean. The name "sudden death" refers to the early defoliation and death of the soybean plant. SDS has become a serious problem in the commercial production of soybeans in North and South America since the early 1990's. Both compounds had a complete inhibition of the two strains to be tested. The extracts have a blocking Croisance that reached $100 \%$. the diffusion method integrates the test molecules in the medium composition that it be degraded by strain of champignon. We can conclude that the compounds $\mathbf{3 a}$ and $\mathbf{3 b}$ are toxic to Fusarium and Verticillium and they play the role of an antifungal (cycloheximide) which blocks protein synthesis in eukaryotic cells and are also used as microbiological growth inhibitor of fungi (antifungal) in the design of culture medium.

Table 3. Antifungal activity of the synthesized compounds

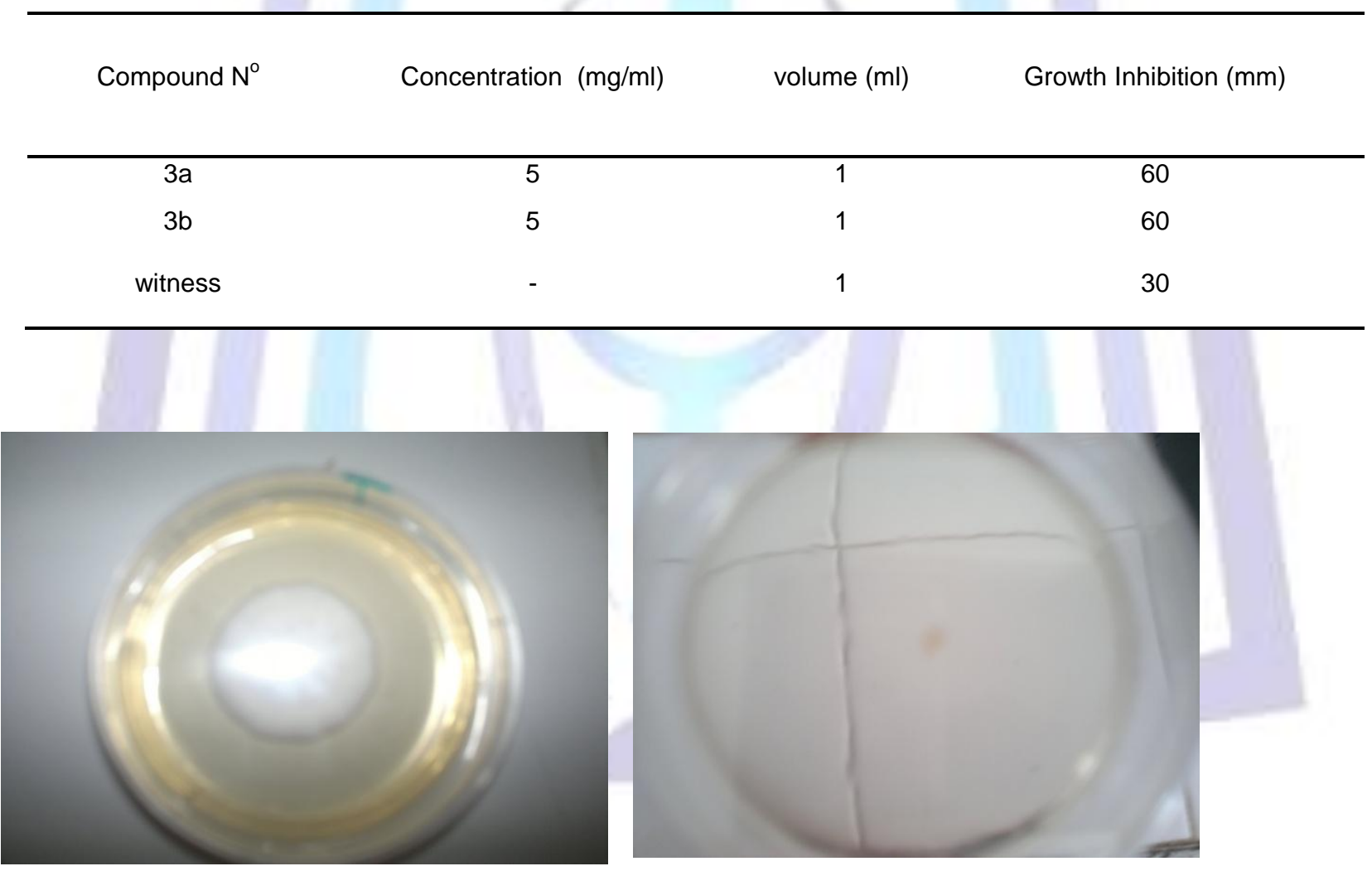

Figure 3: Biological activities of compounds $\mathbf{3 a}$ and $\mathbf{3 b}$ against Fusarium Solani and Verticillum dahlia

We noted that both oxaziridines $\mathbf{3} \mathbf{a}$ and $\mathbf{3} \mathbf{b}$ present the same figure, they inhibit fungal growth in contrast to positive control (PDA).

\section{CONCLUSION}

This study reports the successful synthesis and characterization of dihydroisoquinoline oxaziridines $\mathbf{3 a}$ and $\mathbf{3 b}$. The synthesized compounds were tested for their antifungal activity. Results showed that the tested compounds exhibited a good antifungal activity, paving the way for future investigation in this field. 


\section{EXPERIMENTAL}

\section{Synthesis of imine $2 a$}

To a cooled $\left(0^{\circ} \mathrm{C}\right)$ solution of sulfuric acid $\mathrm{H}_{2} \mathrm{SO}_{4}(95 \%)$ was added dropwise and under magnetic stirring, $1 \mathrm{~mL}$ of acetonitrile in $5 \mathrm{~mL}$ of hexane. Then, $1 \mathrm{~g}$ of tertiary alcohol 1 (commercial product) in $15 \mathrm{ml}$ of hexane was added to the solution.

After return to room temperature, the resulting mixture was stirred at $68^{\circ} \mathrm{C}$ for 2.30 hours. Then, the solution is cooled at the room temperature and poured on ice-cold water under magnetic stirring. The solution is alkalized with ammonia. The organic layer was extracted with dichloromethane, washed with a saturated aqueous $\mathrm{NaCl}$ solution, dried over sodium sulfate and filtered. The solvent was removed in vacuo.

\section{Synthesis of imine $2 b$}

The cold imine $2 \mathrm{a}(500 \mathrm{mg}, 2.80 \mathrm{mmol})$ is added dropwise to $2.5 \mathrm{ml}$ of concentrated sulfuric acid. A solution of $380 \mathrm{mg}$ potassium nitrate in $1.4 \mathrm{ml}$ of sulfuric acid is added dropwise by maintaining the temperature at less than $0^{\circ} \mathrm{C}$. The reactional medium was stirred at room temperature for $2 \mathrm{~h}$ and then at $60^{\circ} \mathrm{C}$ for $4 \mathrm{~h}$. After return to room temperature, the reaction medium is poured on ice-cold water and alkalized with ammonia. The organic phase is extracted with the dichloromethane, washed with a solution saturated in sodium chloride, dried on sodium sulfate, and filtered. The solvent was removed in vacuo.

\section{Synthesis of oxaziridine $3 a$}

By portions, a slight excess of m-chloperbenzoic acid $(415 \mathrm{mg}, 2.40 \mathrm{mmol})$ was added to a solution of imine $2 \mathrm{a}(500 \mathrm{mg}$ $2.29 \mathrm{mmol}$ ) in methanol under magnetic stirring at $0^{\circ} \mathrm{C}$. The reaction was followed by TLC (dichloromethane/ methanol 95:5).

The solvent was evaporated, and the residue obtained was taken up in dichloromethane. The solution was washed with a solution of sodium bicarbonate and then with a saturated solution of sodium chloride. The organic phase was dried on sodium sulfate, filtered, and concentrated. The resulting yellow solid was purified by crystallization from ether/hexane (1:1) afford colorless crystals of oxaziridine $\mathbf{3 a}$.

\section{Synthesis of oxaziridine $3 \mathrm{~b}$}

By portions, a slight excess of $\mathrm{m}$-chloperbenzoic acid $(314 \mathrm{mg}, 1.82 \mathrm{mmol})$ was added to a solution of imine $2 \mathrm{~b}(300 \mathrm{mg}$, $1.73 \mathrm{mmol}$ ) in methanol under magnetic stirring at $0^{\circ} \mathrm{C}$. The reaction was followed by TLC (dichloromethane/ methanol 98:2).

The solvent was evaporated, and the residue obtained was taken up in dichloromethane. The solution was washed with a solution of sodium bicarbonate and then with a saturated solution of sodium chloride. The organic phase was dried on sodium sulfate, filtered, and concentrated.

\section{Characterization of Imines $2 a-b$ and Oxaziridines $3 a-b$}

The Full spectroscopic and characterization data of Imines 2a-b and Oxaziridines 3a-b were reported in our previous work [20]

\section{Antifungal studies}

\section{Preparation of solution}

DMSO stock solutions $(5 \mathrm{mg} / \mathrm{ml})$ of all compounds were prepared with $50 \%$ DMSO in stove incubation.

\section{Preparation of inoculums}

Sland culture of verticillium dahlia and fusarium solani were inoculated into a PDA (Potato dextrose agar) medium in a conical flask and incubated at $25^{\circ} \mathrm{C}$ for 2 days in stove incubation.

\section{Preparation of Medium}

The product was incorporated into PDA culture medium kept molten at arbitrarily selected different proportions. After solidification of the flow and mixing. After that, discs of $3 \mathrm{~mm}$ in diameter were taken from pure cultures of fungi and then deposited in the center of each Petri dish. All plates are incubated at $25^{\circ} \mathrm{C}$.

Mycelial growth was measured daily using a caliper by taking the average of two perpendicular diameters of colonies and the test ends when the hyphae reach the edge of the box in the controls.

The evaluation of the inhibition exerted by this product is estimated by calculating the percent inhibition of mycelial growth of formula ${ }^{[26]}$ :

$$
\mathrm{PI}(\%)=[(\mathrm{A}-\mathrm{B}) / \mathrm{A}] \times 100
$$

A: Average diameter of control colonies

$\mathrm{B}$ : Average diameter of colonies treated with the product 


\section{X-ray crystallography}

The crystal data and experimental details of the data collections and structure refinements are listed in Table 4. Single crystal X-ray diffraction studies were realized on a KPPACCD diffractometer. Solution and refinement: direct methods SHELXS-79 ${ }^{[24]}$ for structure solution and SHELXL97 ${ }^{[25]}$ software package for refinement and data output. All hydrogen positions were calculated.

\section{ACKNOWLEDGMENTS}

Thanks are due to the Ministry of Higher Education and Scientific Research and Technology in Tunisia and Sfax University for financial support.

\section{REFERENCES}

[1] Emmons, W.D. J. Am. Chem. Soc. 1956, 78, 608.

[2] Mlochowski, J.; Kubicz, E.; Kloc, K.; Mordarski, M.; Peczynska, W.; Syper, L. Lieb. Ann.Chem. 1988, 455-464.

[3] Said, S. B.; Mlochowski, J.; Skarzewski, J. Lieb. Ann. Chem. 1990, 461-464.

[4] Ningsanont, N.; Black, D. St. C. ; Chanphen, R.; Thebtaranonth, Y. J. Med. Chem. 2003, 46, 2397.

[5] Peng, L.; Chen, C.; Gonzalez, C.R.; Balogh-Nair, V. Int. J. Mol. Sci. 2002, 3, 1145.

[6] Marchant-Brynaert, J.; Bounkhala-Krouz, Z.; Vanlierde, H.; Ghosez, L. Heterocycles. 1990, 30, 971.

[7] (a) Aubé, J.Chem. Soc. Rev. 1997, 26, 269-277; (b) Kacem, Y.; Kraiem, J.; Kerkeni, E.; Bouraoui, A.; Ben Hassine, B. Eur. J. Pharm. Sci. 2002, 16, 221.

[8] Davis, F. A.; Sheppard, A. C. Tetrahedron. 1989, 45, 5703-5742.

[9] Toda, F.; Tanaka, K. Chem.Lett. 1987, 2283-2284.

[10] Andrae, S.; Schmitz, E. Synthesis. 1991, 5, 327-341.

[11] Davis, F.A.; Sheppard, A.C. Tetrahedron. 1989, 45, 5703-5742.

[12] Mohajer, D.; Iranpoor, N.; Rezaeifard, A. Tetrahedron Lett. 2004, 45, 631-634.

[13] Page,P. C. B.; Heer, J.P.; Bethell, D.; Lund, A.; Collington, E.W.; Andrews, D. M.A. J. Org.chem. 1997, 62, 60936094.

[14] Kraim, J.; Ben Othman, R.; Ben Hassine, B. C. R. Chim. 2004, 7, 1119-1126.

[15] Hata, Y.;Watanabe,M. J.Am. Chem.Soc. 1979, 101, 6671-6679.

[16] Vidal, J.; Damestoy, S.; Guy, L.; Hammachi, J.C.; Aubry, A.; Collet, A . Eur. J. Chem. 1997, 3, 1691- 1709.

[17] (a) Armstrong, A.; Atkin, M. A.; Swallow, S. Tetrahedron Lett. 2000, 41, 2247-2251; (b) Armstrong, A.; Jones, L. H.; Knight, J.D.; Kelsey, R. D. Org. Lett. 2005, 7, 713-716.

[18] Page, P. C. B.;Vahedi, H.; Bethell, D. ; Barkley, J. V. Synth. Commun. 2003, 1943-1949.

[19] (a) Page, P. C. B.; McKenzie, M. J. ; Allina, S. M. ; Buckle, D. R. Tetrahedron. 2000, 56, 9683-9695; (b) Page, P. C. B.; McKenzie, M. J.; Buckle, D. R. Tetrahedron. 1998, 54, 14581-14596.

[20] M.Kammoun; R.Ben Salem and M.Damak. Synth Commun. 2012, 42, 2181-2190.

[21] Shklyaev, V.S.; Aleksandrov, B. B.; Legotkina, G.I.; Vakhrin, M.I.; Gravrilov, M.S.; Mikhailovskii, A.; A. G. Chem. Heterocycl. Comp. 1983, 24, 772-775.

[22] McCoubey, A.; Mathieson, D.W .J. Chem. Soc. 1951, 51, 2851-2853.

[23] Bohé, L.; Kammoun, M. Tetrahedron Lett. 2004, 45, 747-751.

[24] Sheldrick, G. M. Program for Crystal Structure Determination, SHELXS-79, 1979.

[25] Sheldrick, G. M. Program for Crystal Structure Determination, SHELXL-97, 1997.

[26] Dohou, N.; Yamni, K.; Tahrouch, S.; Idrissi Hassani, L.M.; Badoc, A.; Gmira, N. Bull. Soc. Pharm. Bordeaux. 2003, $142,61-78$. 